\title{
PENGGUNAAN LAHAN PERTANIAN BERDASARKAN KOMODITAS UNGGULAN DI KABUPATEN GOWA
}

\author{
(Agriculture of agricultural land use Main commodity in gowa regency)
}

\author{
Anwar \\ Fakultas Pertanian Universitas Muslim Indonesia Makassar \\ Jalan Urip Sumoharjo Km 5 Panakukang, Makassar 90231 Telp. (0411) 455666 \\ anwar.robbo@umi.ac.id
}

\begin{abstract}
The development of agriculture in regional autonomy faces various challenges, both internal and external factors of the region, such as the issue of social inequality and globalization issues. This social and globalization issue demands each region to be able to compete at home and abroad. The gap and globalization has implications for provinces and districts to develop the region and its flagship product. The development of agriculture is one of the sectors that should be the main priority in the development of agribusiness-oriented areas, high productivity, efficient, sustainable, and sustainable. The success of agricultural development determined by the environment in which agricultural commodities are grown, such as food crops, horticulture, plantations, and livestock. This study aims to: (1) know the use of land that can support productivity in Kecamatan Tinggimoncong, and (2) analyze the sector that developed into the leading sector in agricultural development in Kecamatan Tinggimoncong. Based on the use of lahandi Kecamatan Tinggimoncong consist of settlement area, secondary forest, dry land, paddy field, shrubs and open land. The analysis results of Commodity Excellence Revealed (KKT) there are fourteen superior commodities: rice, sweet potato, leek, potato, cabbage, cabbage, tomato, robusta coffee, arabica coffee, cloves, hazelnut, pepper, and vanilla.
\end{abstract}

Keywords: Agricultural land, commodities, productivity, land use

PENDAHULUAN

Pembangunan pertanian diera otonomi daerah menghadapi berbagai tantangan, baik internal maupun faktor eksternal daerah, seperti isu kesenjangan sosial dan isu globalisasi. Isu kesenjangan sosial dan globalisasi ini menuntut tiap daerah untuk mampu bersaing di dalam dan luar negeri. Kesenjangan dan globalisasi berimplikasi kepada provinsi dan kabupaten/kota, untuk melaksanakan percepatan pembangunan ekonomi daerah secara terfokus melalui pengembangan kawasan dan produk andalannya.
Percepatan pembangunan ini bertujuan agar daerah tidak tertinggal dalam persaingan pasar bebas, seraya tetap memperhatikan masalah pengurangan kesenjangan. Karena itu seluruh pelaku memiliki peran mengisi pembangunan ekonomi daerah dan harus mampu bekerjasama melalui bentuk pengelolaan keterkaitan antar sektor, antar program, antar pelaku, dan antar daerah.

Kebutuhan lahan sebagai sumberdaya alam semakin meningkat seiring dengan semakin bertambahnya jumlah penduduk sehingga terjadi 
persaingan dalam penggunaan lahan baik untuk pertanian, perumahan, perkantoran dan lain-lain. Namun disisi lain lahan sebagai sumberdaya alam sangat terbatas, sehingga sering terjadi penggunaan lahan tidak sesuai dengan daya dukung lahan yang menyebabkan terjadinya degradasi lahan. Penebangan hutan secara illegal di daerah pegunungan yang menyebabkan terjadinya degradasi di lahan tersebut seperti : erosi, longsor dan bahkan terjadi banjir. Oleh karena itu diperlukan perencanaan dan pemahaman yang matang terhadap penggunaan lahan yang sesuai dan berkelanjutan. Untuk memanfaatkan lahan secara optimal sesuai dengan penggunaan dan kemampuan lahan dengan memberikan perlakuan sesuai dengan syarat-syarat yang diperlukan agar lahan dapat berfungsi secara berkelanjutan.

Perencanaan penggunaan lahan perlu mengetahui potensi suatu lahan sebagai tahap awal dilakukan evaluasi terhadap kesesuaian dan kemampuan lahan. Menurut Hardjowigeno dan Widiatmaka (2007), bahwa evaluasi lahan merupakan bagian dari proses perencanaan tataguna lahan. Inti evaluasi lahan adalah membandingkan persayaratan yang diminta oleh type penggunaan lahan yang akan diterapkan, dengan sifat-sifat atau kualitas yang dimiliki oleh lahan yang akan digunakan. Dengan cara ini maka akan diketahui potensi lahan atau kelas kesesuaian lahan/kemampuan lahan untuk tipe penggunaan lahan tersebut.

\section{METODE PENELITIAN}

\section{Tempat dan Waktu Penelitian}

Penelitian dilaksanakan di Kecamatan Tinggimoncong Kabupaten Gowamulai bulan September sampai dengan bulan Desember 2017.

\section{Bahan dan Alat Penelitian}

Bahan yang digunakan dalam penelitian ini adalah peta administrasi, peta penutupan lahan, peta jenis tanah, dan petalereng dengan skala $1: 100.000$.

Alat yang digunakan dalam penelitian ini adalah meteran, abney level, dan alat tulis menulis.

\section{Pengumpulan Data}

Data yang digunakan dalam penelitan ini terdiri atas data sekunder seperti: peta lereng, peta penupan lahan, peta jenis tanah, data BPS Kabupaten Gowa dan Kecamatan Tinggi Moncong serta laporan yang berhubungan dengan penelitian. Selain data sekunder juga 
dibutuhkan data primer yaitu data analisa Keunggulan Komparatif pengamatan langsung di lapang.

Terungkap (KKT) dengan rumus adalah :

\section{Analisis Data}

\section{Penggunaan Lahan}

Menganalisis Peta Penutupan lahan di Kecematan Tinggi Moncong menggabungkan hasil identifikasi karakteristik fisik lahan di daerah penelitian.

\section{Analisis Sektor Basis Wilayah}

Kemampuan memacu per-

tumbuhan suatu wilayah sangat tergantung dari keunggulan atau daya saing sektorsektor ekonomi di wilayahnya. Untuk mengetahui potensi aktivitas ekonomi yang merupakan indikator sektor basis dan bukan basis dapat digunakan metode location question, yang merupakan perbandingan relative antara kemampuan sektor yang sama pada daerah yang lebih luas dalam suatu wilayah (Ruastiadi, et $a l, 2009)$. Selain itu untuk mengetahui komoditas unggulan wilayah studi bisa juga memakai metode analisa keunggulan komparatif terungkap yang dimodifikasi sesuai dengan data yang tersedia (Dirjen Perenc. Teknis Pengembangan Masyarakat dan Kawasan Depnakertrans, 2006). Pada penelitian ini menggunakan

$$
K K T=\frac{X i / X p r}{X i k / X p r k}
$$

Keterangan :

$\mathrm{KKTi}=$ Nilai Komparatif terungkap komoditas-i di daerah studi

$\mathrm{Xi}=$ Jumlah $\mathrm{n}$ ilai ekspor komoditasi didaerah studi

$\mathrm{Xpr}=$ Jumlah nilai total hasil pertanian didaerah studi (termasuk komoditasi)

$\mathrm{Xik}=$ Jumlah total nilai ekspor komoditas-i dari kab/prop

Xpr k = Jumlah total nilai ekspor hasil pertanian dari kab/prop

Interpretasi dari perhitungan KKT ini adalah :

$>$ Jika KKT> 1 : artinya komoditas unggulan

Jika KKT< 1: artinya bukan komoditas unggulan

Bila di daerah studi belum ada ekspor, maka nilai ekspor dapat dimodifikasi yaitu jumlah produksi dikali dengan harga jual komoditas tersebut.

\section{HASIL DAN PEMBAHASAN}

Berdasarkan peta Penutupan Lahan sebagai acuan dalam mengidentifikasi penggunaan lahan dan pengamatan lapang. Berdasarkan peta penutupan lahan serta pengamatan lapang di Kecamatan Tinggi Moncong masing-masing: 

1. Penutupan Lahan Pemukiman. yaitu: Desa Parigi, Garassi, Gantarang, Tersebar diseluruh desa dan dan kelurahan Malino.

kelurahan.

4. Penutupan Lahan Sawah. Lahan sawah

2. Penutupan Lahan Hutan Sekunder. ini hanya terdapat di Desa Bulutana.

Lahan hutan sekunder tersebar 5. Penutupan Lahan Semak Belukar.

dibeberapa desa yaitu: Desa Parigi, Lahan semak belukar tersebar diseluruh

Garassi, Bulutana, Pattapang dan desa dan kelurahan.

Bontorerung.

6. PenutupanLahan Tanah terbuka. Lahan

3. PenutupanPertanian Lahan Kering. ini terdapat di Desa Parigi dan Lahan kering tersebar dibeberapa desa Bontorerung.

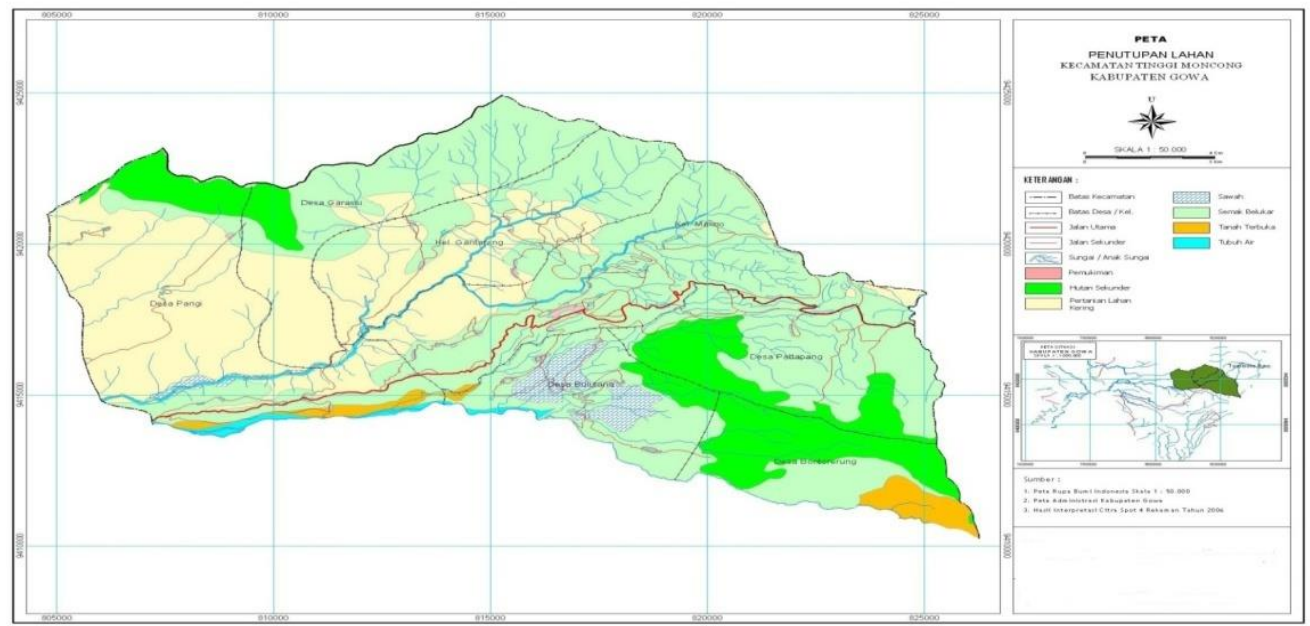

Gambar 1. Peta Penutupan Lahan

\section{Analisis Sektor Unggulan}

Usaha peningkatan dan pengembangan budidaya tanaman dengan memperhatikan keunggulan suatu komoditas yang meliputi keunggulan komparatif, keunggulan kompetitif, dan kelayakan usaha. Oleh karena itu mememiliki daya saing, harga, katersediaan produksi, dan penerapanya dengan teknologi.
Identifikasi sektor unggulan dengan metode Analisis Keunggulan Komoditas Terungkap (KKT) yang telah dikembangkan oleh Direktorat Perencanaan Teknis Pengembangan Masyarakat Dan Kawasan, Direktorat Jenderal Pembinaan Pengembangan Masyarakat dan Kawasan Transmigrasi, yang telah dimodifikasi sesuai dengan data yang tersedia dimana nilai ekspor suatu komoditas dari daerah penelitian 
dimodifikasi dengan nilai produksi yaitu jumlah produksi dikali dengan harga jual komoditas tersebut. Hasil analisis ini dapat dijadikan sebagai indikator untuk menentukan sektor unggulan suatu komoditas.

\section{Hasil analisis KKT>1 berarti} komoditi tersebut menjadi basis atau merupakan komoditi unggulan di Kecamatan Tinggimoncong, hasilnya tidak saja dapat memenuhi kebutuhan diwilayah bersangkutan akan tetapi juga dapat di kirim keluar wilayah. Bila KKT< 1 berarti komoditi tersebut tergolong non basis, tidak unggul di Kecamatan Tinggimoncong.

Analisis KKT dilakukan setiap tahun selama 5 (lima) terakhir kemudian dirata-ratakan untuk mendapatkan nilai KKT yang lebih akurat. Kecuali sub sektor tanaman hortikultura hanya dianalisis 2 (dua) tahun terakhir terkait data di kecamatan yang tidak lengkap.

Tabel 1. Hasil Analisis Keunggulan Komparatif Terungkap (KKT) Tanaman Pangan di Kecamatan Tinggimoncong.

\begin{tabular}{clcccccc}
\hline \multirow{2}{*}{ No. } & \multirow{2}{*}{ Tanaman Pangan } & \multicolumn{5}{c}{$\mathrm{T} \mathrm{a} \mathrm{h} \mathrm{u} \mathrm{n}$} & \multirow{2}{*}{ Rata-rata } \\
\cline { 3 - 6 } & & 2012 & 2013 & 2014 & 2015 & 2016 & \\
\hline 1 & Padi Sawah & 2,10 & 1,56 & 0,24 & 2,96 & 2,26 & 1,82 \\
3 & Jagung & 0,07 & 0,00 & 0,00 & 0,01 & 0,02 & 0,02 \\
4 & Kacang Tanah & 0,00 & 0,00 & 0,00 & 0,00 & 4,12 & 0,82 \\
4 & Ubi Kayu & 0,59 & 0,13 & 1,59 & 0,18 & 0,05 & 0,51 \\
6 & Ubi Jalar & 3,04 & 3,67 & 2,61 & 3,25 & 0,20 & 2,55 \\
\hline
\end{tabular}

Sumber : Data Diolah 2017

Berdasarkan Tabel 1, hasil analisis dengan metode Keunggulan Komparatif Terungkap (KKT) tanaman pangan ratarata 5 (lima) tahun terakhir, terdapat 2 (dua) komoditas unggulan adalah padi $(1,82)$ dan ubi jalar $(2,55)$. Sedangkan tanaman jagung, kacang tanah, ubi kayu dan kacang kedelai tidak masuk komoditas unggulan. Tapi berdasarkan data 4 (empat) tahun terakhir kacang tanah dan kacang kedelai belum dibudidayakan. namun ada kecenderungan menjadi komoditas unggulan berdasarkan data tahun 2016 dengan nilai KKT masingmasing 4,12 dan 2,07.

Nilai KKT padi sawah dan ubi jalar yang berubah-ubah setiap tahun dipengaruhi oleh jumlah produksi dan harga produksi. Meskipun nilai KKT padi sawah pada tahun 2014 dan ubi jalar pada tahun 2016 kurang dari 1, tetapi rata-rata nilai KKT selama 5 (lima) terakhir masih 
termasuk katagori komoditas unggulan. desa, sementara budidaya ubi jalar Penyebaran padi sawah hanya beberapa menyebar setiap desa.

Tabel 2. Hasil Analisis Keunggulan Komparatif Terungkap (KKT) Tanaman Hortikultura di Kecamatan Tinggimoncong.

\begin{tabular}{clrrr}
\hline \multirow{2}{*}{ No. } & Tanaman & \multicolumn{2}{c}{ T a h u n } & \multirow{2}{*}{ Rata-rata } \\
\cline { 3 - 4 } & Hortikultura & 2015 & 2016 & 1,00 \\
\cline { 3 - 4 } 1 & Bawang daun & 0,99 & 1,00 & 1,00 \\
2 & Kentang & 1,00 & 1,00 & 1,00 \\
3 & Kubis/kol & 1,00 & 1,00 & 1,00 \\
4 & Petsai/Sawi & 0,98 & 1,00 & 1,00 \\
5 & Wortel & 1,00 & 1,00 & 1,00 \\
6 & Tomat & 0,99 & 1,00 & \\
\hline
\end{tabular}

Sumber : Data Diolah 2017

Berdasarkan Tabel 2, hasil analisis masuk komoditas unggulan yaitu: dengan metode Keunggulan Komparatif bawang daun (1,00), kentang (1,00), Terungkap (KKT) tanaman hortikultura kubis/kol $(1,00)$, petsai/sawi $(1,00)$, wortel rata-rata 2 (dua) tahun terakhir,semuanya $(1,00)$ dan tomat $(1,00)$.

Tabel 3. Hasil Analisis Keunggulan Komparatif Terungkap (KKT) Tanaman Perkebunandi Kecamatan Tinggimoncong.

\begin{tabular}{llrrrrrr}
\hline & \multirow{2}{*}{ Nanaman } & \multicolumn{5}{c}{ T a h u n } & \multirow{2}{*}{ Rata-rata } \\
\cline { 3 - 6 } & Perkebunan & 2012 & 2013 & 2014 & 2015 & 2016 & \\
\hline 1 & Kelapa dalam & 0,02 & 0,02 & 0,02 & 0,02 & 0,02 & 0,02 \\
2 & Kopi Robusta & 4,28 & 2,03 & 3,56 & 4,91 & 3,11 & 3,58 \\
3 & Kopi Arabika & 0,93 & 4,82 & 0,89 & 1,18 & 0,89 & 1,74 \\
4 & Kakao & 0,43 & 0,21 & 0,41 & 0,52 & 0,31 & 0,38 \\
5 & Cengkeh & 1,20 & 1,15 & 2,14 & 2,83 & 3,09 & 2,08 \\
6 & Jambu Mente & 0,09 & 0,04 & 0,05 & 0,07 & 0,04 & 0,06 \\
7 & Kemiri & 1,97 & 0,93 & 1,71 & 2,29 & 3,28 & 2,04 \\
8 & Lada & 6,47 & 3,00 & 5,38 & 7,40 & 5,73 & 5,60 \\
9 & Vanili & 6,33 & 3,50 & 5,17 & 7,04 & 5,68 & 5,54 \\
\hline
\end{tabular}

Sumber : Data Diolah 2017

Berdasarkan Tabel 3, hasil analisis dan vanili (5,54). Tanaman kelapa dalam, dengan metode Keunggulan Komparatif kakao, dan jambu mente tidak masuk Terungkap (KKT) tanaman perkebunan komoditas unggulan.

rata-rata 5 (lima) tahun terakhir, terdapat Suatu komoditas unggul bila 6(enam) komoditas unggulan yaitu: kopi komoditas tersebut menghasilkan robusta (3,58), kopi arabika $(1,74)$, produksi yang dapat mensuplai atau cengkeh $(2,08)$, kemiri $(2,04)$, lada $(5,60)$, dikirim ke daerah lain sehingga diharapkan 
mampu mendatangkan pendapatan wilayah. komoditas dan tanaman perkebunan 6 Menurut Hendayana (2003), hal tersebut komoditas. Sebagai komoditas unggulan karena areal panen merupakan resultante dalam pengembangan wilayah kesesuaian tumbuh tanaman dengan mempunyai peluang besar untuk kondisi agroekologi yang secara implisit menggerakkan perekonomian wilayah. mencakup unsur-unsur iklim, fisiografi dan Untuk mewujudkan keadaan tersebut jenis tanah sehingga secara agregat di dibutuhkan dukungan yang kuat dari wilayah kecamatan tersebut menghasilkan pemerintah dan pengusaha atau surplus produksi yang memungkinkan stakeholder.

untuk mengekspor surplus itu keluar wilayah dan akhirnya mampu mendatangkan pendapatan wilayah.

\section{Penggunaan Lahan}

Penggunaan lahan di daerah penelitian berdasarkan peta penutupan lahan adalah: hutan, tegalan/kebun campuran, sawah, tanah terbuka dan pekarangan/pemukiman. Untuk penggunaan lahan untuk pertanian terdiri dari tanaman pangan, hortikultura, dan tanaman perkebunan.

Hasil analisis KKT menunjukkan bahwa terdapat 14 (empat belas) komoditas unggulan di daerah penelitian, masing-masing tanaman pangan 2 (dua) komoditas, tanaman hortikultura 6 (enam)

\section{Sub Sektor Tanaman Pangan}

Berdasarkan analisis KKT sub sektor tamaman pangan yang diamati, padi sawah dan ubi jalar menjadi komoditas unggulan. Produksi padi sawah rata-rata 6,10 ton/ha selama 5 (lima) tahun terakhir meskipun berdasarkan data BPS Kabupaten Gowa tahun 2012-2016 produksi padi sawah cenderung berfluktuasi. 
Tabel 4. Produksi Komoditas Unggulan Sub Sektor Tanaman Pangan di Kecamatan Tinggimoncong.

\begin{tabular}{ccccccc}
\hline & & 2012 & 2013 & 2014 & 2015 & 2016 \\
\cline { 3 - 6 } No. & $\begin{array}{c}\text { Tanaman } \\
\text { Pangan }\end{array}$ & $\begin{array}{c}\text { Produksi } \\
\text { (ton/ha) }\end{array}$ & $\begin{array}{c}\text { Produksi } \\
\text { (ton/ha) }\end{array}$ & $\begin{array}{c}\text { Produksi } \\
\text { (ton/ha) }\end{array}$ & $\begin{array}{c}\text { Produksi } \\
\text { (ton/ha) }\end{array}$ & $\begin{array}{c}\text { Produksi } \\
\text { (ton/ha) }\end{array}$ \\
\hline 1 & Padi & 6,08 & 5,04 & 6,49 & 6,67 & 6,08 \\
2 & Ubi Jalar & 13,72 & 12,12 & 12,37 & 12,52 & 11,00 \\
\hline
\end{tabular}

Sumber: Data Diolah 2017

Usaha menjaga agar padi sawah Usaha mempertahankan ubi jalar sebagai agar tetap menjadi komoditas unggulan lomoditas unggulan adalah penggunaan yaitu : penggunaan bibit unggul, bibit unggul dan upaya sosialisasi penggunaan pupuk, pemberantasan hama budidaya ubi jalar sebagai bahan dan penyakit, menanam berdasarkan diversifikasi pangan.

kalender tanam yang telah ditetapkan. Selain itu ada upaya pemerintah untuk swasembada padi, sehingga Kecamatam Tinggimoncong menjadi lumbung padi.

Ubi jalar merupakan komoditas unggulan sub sektor tanaman pangan. Rata-rata produksi ubi jalar 12,14 ton/ha. Berdasarkan data produksi tahun 20122016 produksi cenderung menurun seiring dengan menurunnya luas areal produksi. Oleh karena itu diperlukan dukungan dari pemerintah untuk meningkatkan produksi dan ketersediaan areal tanam.

\section{Sub Sektor Tanaman Hortikultura}

Budidaya tanaman sayuran atau hortikultura banyak diusahakan petani di Kelurahan Pattapang dan dilakukan secara intensif, hal ini ditandai dengan adanya penanaman yang sepanjang tahun karena ditunjang oleh curah hujan yang cukup merata. Berbagai jenis tanaman seperti: bawang daun, kentang, kol/kubis, petsai/sawi, wortel dan tomat. Berdasarkan Analisis KKT keenam tanaman hortikultura yang diamati semuanya termasuk komoditas unggulan. 

Tabel 5. Produksi Komoditas Unggulan Sub Sektor Tanaman Hortikultura Kecamatan Tinggimoncong.

\begin{tabular}{cccc}
\hline \multirow{2}{*}{ No. } & \multirow{2}{*}{$\begin{array}{c}\text { Tanaman } \\
\text { Hortikultura }\end{array}$} & 2015 & 2016 \\
\cline { 3 - 4 } & & Produksi (ton/ha) & Produksi (ton/ha) \\
\hline 1 & Bawang daun & 0,71 & 0,10 \\
2 & Kentang & 0,91 & 0,18 \\
3 & Kubis & 0,04 & 0,13 \\
4 & Persai/Sawi & 0,06 & 0,13 \\
5 & Wortel & 0,03 & 0,09 \\
6 & Tomat & 0,05 & 0,22 \\
\hline Sumber: Data Diolah 2017 & &
\end{tabular}

Usaha mempertahankan bawang konservasi tanah untuk mengendalikan daun, kentang, kol/kubis, petsai/sawi, erosi berupa teras dan penanaman dengan wortel dan tomat agar tetap menjadi mengikuti garis kontur. Tetapi masih ada komditas unggulan yaitu: penggunaan petani belum menerapkan teknik bibit unggul, penggunaan pupuk, konservasi dengan alasan mengurangi luas penggunaan bahan organik, lahan apabila dibuat teras. Hasil pemberantasan hama dan penyakit serta penelitian Rukayya (2010) menunjukkan pengelolaan lahan sesuai dengan prinsip pengelolaan lahan untuk tanaman kubis konservasi tanah dan air.

Peningkatan sumberdaya petani pada kemiringan lereng yang curam dan dalam pengembangan budidaya tanaman tidak menerapkan teknik konservasi berupa teras mempunyai nilai erosi paling hortikultura di dataran tinggi telah tinggi diantara berbagai penggunaan lahan dibentuk kelompok tani Veteran di hortikultura di hulu DAS Jeneberang Bulubalea. Usaha tani yang dikelola oleh Kecamatan Tinggimoncong berkisar anggota kelompok tani Veteran dari tahun 346,12 ton/ha/tahun. Pada pertanaman ketahun terus berkembang. Selain kentang di Hulu DAS Jeneberang, erosi kelompok tani Veteran Bulubalea terdapat yang terjadi dapat mencapai 223,11 juga Lembaga Swadaya Masyarakat P4S ton/ha/tahun dan masuk kategori tingkat Bulubalea (Pusat Palatihan Pertanian bahaya erosi sangat berat (Saida, Pedesaan Swadaya) Bulubalea. Abdullah, dan Ilsan, 2017).

Pengelolaan lahan pada budidaya hortikultura di daerah penelitian umumnya para petani sudah menerapkan teknik 
Sub Sektor Tanaman Perkebunan

Tanaman sub sektor perkebunan terdapat 6 (enam) komoditas unggulan berdasarkan analisis KKT adalah kopi Tinggimoncong.

Tabel 6. Produksi Komoditas Unggulan Sub Sektor Tanaman Perkebunan Kecamatan Tinggimoncong.

\begin{tabular}{ccccccc}
\hline & & 2012 & 2013 & 2014 & 2015 & 2016 \\
\cline { 3 - 6 } No. & $\begin{array}{c}\text { Tanaman } \\
\text { Perkebunan }\end{array}$ & $\begin{array}{c}\text { Produksi } \\
\text { (ton/ha) }\end{array}$ & $\begin{array}{c}\text { Produksi } \\
\text { (ton/ha) }\end{array}$ & $\begin{array}{c}\text { Produksi } \\
\text { (ton/ha) }\end{array}$ & $\begin{array}{c}\text { Produksi } \\
\text { (ton/ha) }\end{array}$ & $\begin{array}{c}\text { Produksi } \\
\text { (ton/ha) }\end{array}$ \\
\hline 1 & Kopi Robusta & 0,22 & 0,24 & 0,67 & 0,76 & 0,17 \\
2 & Kopi Arabika & 0,35 & 0,43 & 0,70 & 0,76 & 0,36 \\
3 & Cengkeh & 0,09 & 0,43 & 0,60 & 0,65 & 0,24 \\
4 & Kemiri & 0,43 & 0,44 & 0,62 & 0,65 & 0,23 \\
5 & Lada & 0,28 & 0,28 & 0,23 & 0,30 & 0,20 \\
6 & Vanili & 0,09 & 0,13 & 0,16 & 0,22 & 0,05 \\
\hline
\end{tabular}

Sumber: Data Diolah 2017

Berdasarkan tabel 6, produksi KESIMPULAN DAN SARAN komoditas unggulan sub sektor tanaman perkebunan dimana produksi dari tahun 2012-2015 selalu meningkat, tetapi tahun 2016 produksi menurun. Meskipun demikian hasil analisis KKT tahun 2016 masih termasuk komoditas unggulan.

Usaha untuk memepertahankan kopi robusta, kopi arabika, cengkeh, kemiri,lada, dan vanili agar tetap menjadi komoditas unggulan adalah pemeliharaan, pemupukan dan pemberantasan hama penyakit. Selain itu diperlukan peningkatan sumberdaya petani melalui sekolah lapang petani dan pemberdayaan kelompok tani. robusta, kopi arabika, cengkeh, kemiri, lada, dan vanili. Oleh karena itu sangat layak dibudidayakan di Kecamatan 0,22 0,05 
komoditas (bawang daun, kentang, kol/kubis, petsai/sawi, wortel dan tomat) dan sub sektor tanaman perkebunan enam komoditas (kopi robusta, kopi arabika, cengkeh, kemiri,lada, dan vanili).

\section{Saran-saran}

1. Komoditi unggulan di Kecamatan Tinggimoncong tetap dipertahankan dan diusahakan menjadi lebih berkembang lagi.

2. Diperlukan pembinaan yang intensif kepada masyarakat dalam penggunaan lahan agar tetap diguanakan secara berkelanjutan.

\section{DAFTAR PUSTAKA}

Anonim, 2013. Penggunaan Lahan https://petatematikindo.wordpress.c om/ 2013/01/06/ penggunaan lahan/. Diakses 14 September 2017.

Anonim, 2015. Penggunaan Lahan dan Pola Pemukuman https: //www.slideshare.net/AbdulHafiz28/ penggunaan-lahan-dan-polapemukiman. Diakses 12 September 2017.

Arsyad, S. 2006. Konservasi Tanah dan Air.IPB Press. Bogor.

Badan Perencanaan Pembangunan Daerah[Bappeda] Kabu-paten Gowa. 2003. Rencana Tata Ruang Wilayah (RTRW) Kabupaten Gowa.
Badan Pusat Statistik Kabupaten Gowa. 2012. Gowa Dalam Angka 2012. Kerjasama BPS dan BAPPEDA Kabupaten Gowa.

Badan Pusat Statistik Kabupaten Gowa. 2013. Gowa Dalam Angka 2013. Kerjasama BPS dan BAPPEDA Kabupaten Gowa.

Badan Pusat Statistik Kabupaten Gowa. 2014. Gowa Dalam Angka 2014. Kerjasama BPS dan BAPPEDA Kabupaten Gowa.

Badan Pusat Statistik Kabupaten Gowa. 2015. Gowa Dalam Angka 2015. Kerjasama BPSdan BAPPEDA Kabupaten Gowa.

Badan Pusat Statistik Kabupaten Gowa. 2016. Gowa Dalam Angka 2016. Kerjasama BPS dan BAPPEDA Kabupaten Gowa.

Badan Pusat Statistik Kabupaten Gowa. 2012. Kecamatan Tinggimoncong Dalam Angka 2012. BPS Kabupaten Gowa.

Badan Pusat Statistik Kabupaten Gowa. 2013. Kecamatan Tinggimoncong Dalam Angka 2013. BPS Kabupaten Gowa.

Badan Pusat Statistik Kabupaten Gowa. 2014. Kecamatan Tinggimoncong Dalam Angka 2014. BPS Kabupaten Gowa.

Badan Pusat Statistik Kabupaten Gowa. 2015. Kecamatan Tinggimoncong Dalam Angka 2015. BPS Kabupaten Gowa.

Badan Pusat Statistik Kabupaten Gowa. 2016. Kecamatan Tinggimoncong 
Dalam Angka 2016. BPS Kabupaten Gowa.

Badan Pusat Statistik Kabupaten Gowa. 2015. Statistik Pertanian Tanaman Hortikultura 2015. BPS Kabupaten Gowa.

Badan Pusat Statistik Kabupaten Gowa. 2016. Statistik Pertanian Tanaman Horti-kultura 2016. BPS Kabupaten Gowa.

Direktorat Perencanaan Teknis Pengembangan Masyarakat dan Kawasan, Dirjen Pembinaan dan Pengembangan Masyarakat dan Kawasan Transmigrasi Depnakertrans, 2006. Pedoman Penyusunan Rencana Pengembangan Kota Terpadu Mandiri.

Haridjaja, O,. 2008. Pentingnya Konservasi Sumberdaya Lahan. Dalam : Penyelamatan Tanah, Air, dan Lingkungan. Edt.: S. Arsyad dan E. Rustiadi. Crestpent Press dan Yayasan Obor Indonesia. Jakarta.

Hardjowigeno, S. dan Widiatmaka. 2007. Evaluasi Kesesuaian Lahan dan Perencanaan Tataguna Lahan. Gadjah Mada University Press. Yogyakarta.

Hendayana, R. 2003. Aplikasi Metode Location Quotient (LQ) Dalam Penentuan Komoditas Unggulan Nasio-nal. Informatika Pertanian Volume 12. Jakarta.

Nasoetion, L. Ibrahim, 2008. Aspek Keagrarian dalam Pengelolaan Tanah. Dalam : Penyelamatan Tanah, Air, dan Lingkungan. Edt.: S. Arsyad dan E. Rustiadi. Crestpent
Press dan Yayasan Obor Indonesia. Jakarta.

Prahasta, E. 2009. Sistem Informasi Geogarafis : Konsep-konsep Dasar (Perspektif Geodesi dan Geomatika). Informatika. Bandung.

Rayes, L. 2007. Metode Inventarisasi Sumber Daya Lahan. Andi Yokyakarta

Rukayya. 2010. Prediksi Erosi dan Pemilihan Agroteknologi Di Lahan Hortikultura DAS Jeneberang Bagian Hulu Kecamatan Tinggimoncong Kabupaten Gowa Sulawesi Selatan (Skripsi) Program Studi Agroteknologi, Fakultas Pertanian, Universitas Muslim Indonesia, Makassar.

Rustiadi, E., Sunsun S., Dyah R. Panuju., 2009. Perencanaan dan Pengembangan wilayah. Crestpent Press dan Yayasan Obor Indonesia. Jakarta

Saida, Abdullah, dan M. Ilsan. 2017. Erosi dan Tingkat Bahaya Erosi pada Pertanaman Kentang. Jurnal Agrotek: Vol 1 (2) hal: 1-13. Fakultas Pertanian UMI Makassar.

Salamba, H. N, 2014. Pewilayahan Komoditas Pertanian Berdasarkan Komoditas Unggulan Dan Kesesuaian LahanDi Kabupaten Bolaang Mongondow Selatan Provinsi Sulawesi Utara. (Tesis) Program Studi Ilmu Tanah, Sekolah Pascasarjana, Institut Pertanian Bogor, Bogor

Saptana, Sumaryanto dan Supena Friyatno (2010). Analisis Keunggulan Komparatif dan Kompetitif 
Komoditas Kentang dan Kubis Di Wonosobo Jawa Tengah. Pusat Penelitian dan Pengembangan Sosial Ekonomi Pertanian, Bogor.

Saputra, R. K. 2009. Strategi Pengembangan Wilayah Kota Metro Provinsi Lampung Berbasis Evaluasi Kemampuan dan Kesesuaian Lahan. (Tesis) Ilmu Perencanaan Wilayah, Program Studi Perencanaan Wilayah, Sekolah Pascasarjana, Institut Pertanian Bogor, Bogor.

Sitorus, S. R. P. 2004. Evaluasi Sumberdaya Lahan. Tarsito. Bandung.

Soepratohardjo,H., Soehadi, Moerdani, Soewardjo, Herman S, Hardjo As, Moh. Soleh, Junus Dai, Soehardjo, dan Soekardi M,.1967. Pedoman Pengamatan Tanah Dilapang. Lembaga Penelitian Tanah bogor, Bogor

Tarigan, R. 2009. Ekonomi Regional: Teori dan Aplikasi. Bumi Aksara. Jakarta.

Wulandari, Nur Indah. 2010. Penentuan Agribisnis Unggulan Komoditi Pertanian Berdasarkan Nilai Produksi Di Kabupaten Grobogan (Tesis). Program Studi Agribisnis Program Pascasarjana,Universitas Diponegoro, Semarang. 